This item was submitted to Loughborough's Research Repository by the author.

Items in Figshare are protected by copyright, with all rights reserved, unless otherwise indicated.

\title{
Impact of rapid manufacturing on design for manufacture for injection moulding
}

PLEASE CITE THE PUBLISHED VERSION

PUBLISHER

Professional Engineering Publishing / @ IMECHE

VERSION

VoR (Version of Record)

LICENCE

CC BY-NC-ND 4.0

\section{REPOSITORY RECORD}

Mansour, S., and Richard J.M. Hague. 2019. "Impact of Rapid Manufacturing on Design for Manufacture for Injection Moulding". figshare. https://hdl.handle.net/2134/4769. 
This item was submitted to Loughborough's Institutional Repository (https://dspace.lboro.ac.uk/) by the author and is made available under the following Creative Commons Licence conditions.

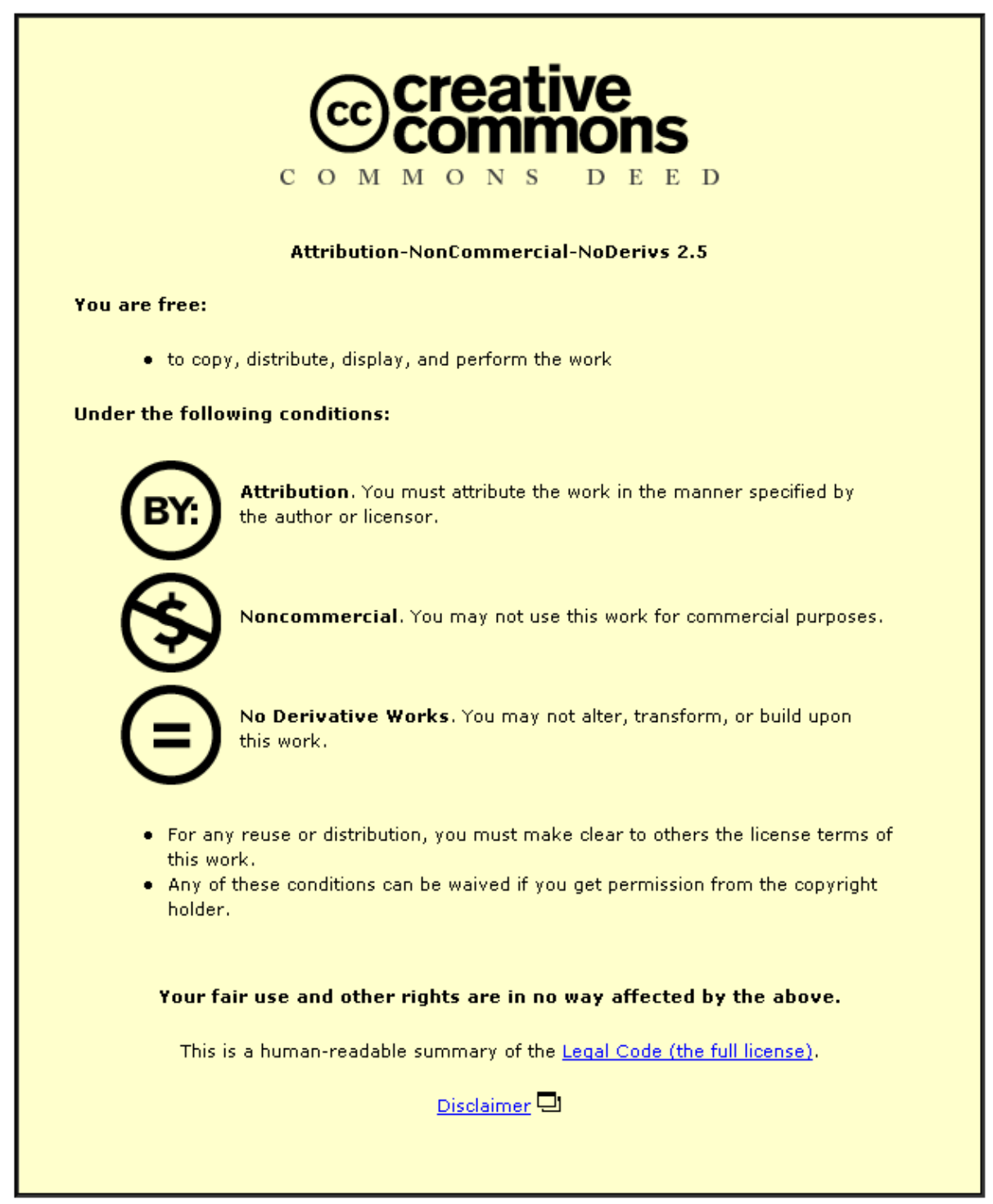

For the full text of this licence, please go to: http://creativecommons.org/licenses/by-nc-nd/2.5/ 


\title{
Impact of rapid manufacturing on design for manufacture for injection moulding
}

\author{
S Mansour* and R Hague \\ Rapid Manufacturing Research Group, The Wolfson School of Mechanical and Manufacturing Engineering, \\ Loughborough University, Leicestershire, UK
}

\begin{abstract}
Rapid manufacturing (RM) employs similar technologies and processes to rapid prototyping (RP), hence resulting in a tool-less manufacturing process. This is achieved by assuming that RP machines have been converted to proper manufacturing machines. The current approaches to the design process, product development cycle and manufacturing considerations at the design stage within a concurrent engineering environment are closely examined. An attempt is then made to investigate the effect of the RM processes on the design process and product development cycle. This is further expanded to consider the impact of RM on rules and guidelines that have been established for design for manufacturing (DFM). This paper is limited to a comparison of RM with regards to injection moulding as RM is most likely to compete with this process in the first instance. This is the first research work to investigate the impact of RM on the design process.
\end{abstract}

Keywords: rapid prototyping, rapid manufacturing, design for $X$, design for manufacturing, injection moulding

\section{INTRODUCTION}

Rapid prototyping (RP) is the collective name of a set of different technologies and processes used to manufacture models directly from a three-dimensional computer aided design (CAD) model by constructively building them in layers. Other associated names are solid freeform fabrication (SFF) and layered manufacturing. Rapid prototyping technologies have gained diversity, complexity, sophistication and popularity since their introduction in the late 1980s. The main feature of all RP processes is the ability to create parts of any geometry and complexity automatically without any tooling or skilled craftsman. This is usually achieved without the need for any, or with the need for very little, machine set-up.

Rapid manufacturing (RM) is evolving from RP technologies that produce parts directly from a threedimensional CAD model without the use of tools. By far the most important feature of RM is the tool-less manufacturing of parts. This is very important for

The MS was received on 7 June 2002 and was accepted after revision for publication on 24 October 2002.

*Corresponding author: Rapid Manufacturing Research Group, The Wolfson School of Mechanical and Manufacturing Engineering, Loughborough University, Loughborough, Leicestershire LE11 3TU, UK. producing parts of complex geometry and could result in reducing the lead time and, ultimately, the overall manufacturing costs. Rapid manufacturing offers the potential to change the paradigm of manufacturing, service and distribution with opportunities for producing highly complex, custom-made products at low cost in or outside the conventional factory, possibly by distributor, retailer or customer. Rapid manufacturing will affect manufacturers and customers alike. For manufacturers, costs will be dramatically reduced as no tooling is required, and for customers, affordable, complex, individualized products will be cost effectively made that can be configured to personal use, thus giving the potential for much greater product satisfaction [1].

Another important feature is the potential to build parts of single or multiple materials, or for materials to be varied in a controlled manner at any point within a part [2-4]. However, it should be emphasized that work has taken place at a research level and that no commercial machines are yet available. It is considered likely that commercial RM machines will be available within 5-10 years, with multimaterial systems likely in $10-15$ years [5]. Rapid manufacturing will have a major impact on the manufacturing industry and can almost be termed the next industrial revolution [6].

A product development process is the sequence of steps or activities that an enterprise employs to conceive, 
design and commercialize a product [7]. Many of these steps and activities are intellectual and organizational rather than physical. Some organizations, depending on their size and nature, define and follow a precise and detailed development cycle, while others may not even be able to describe their processes. Furthermore, every organization employs a process that is at least slightly different from that of every other organization. In fact, the same enterprise may follow a different cycle for each of several different types of product. Some of these steps are related to design, prototyping and testing, while others consider manufacturing, assembly, serviceability and sustainability. There are other steps such as marketing, procurement, commercialization, etc.

An EPSRC-funded research project [8] is currently being undertaken by the authors at the University of Loughborough and is investigating the impacts on the design process and product development cycle of the advent of RM.

\section{LIMITATIONS AND OBJECTIVES}

Current RP machines cannot be considered as full RM machines as the produced parts have certain inherent drawbacks and limitations. Poor surface finish (the stair stepping effect due to the nature of the layered manufacturing process), lack of dimensional accuracy and close tolerances have long been considered the Achilles heels with regard to RP processes [9-14]. Also, the range of materials available to these processes at present is limited and expensive in comparison with existing manufacturing materials such as polypropylene, glass-filled nylon and ABS [15]. Another constraint is the build time, especially for large parts, which is very slow compared with injection moulding for mass production purposes [16].

Therefore, for this paper it is assumed that the above-mentioned problems such as build time, material properties, accuracy and surface finish have been resolved, and that RP machines have been successfully converted to full functional RM systems. The aim of this paper is firstly to investigate the product development cycle and its different building blocks, as described by various researchers, and then to investigate the impact of RM on the design for manufacturing approach for injection moulding.

\section{RAPID PROTOTYPING}

It is not the aim of this paper to describe various RP processes, as they are well documented elsewhere [17-19]. Suffice to say that more than 920 patents on these technologies have been awarded in the United States alone [20]. There are many processes that never gained any popularity among users and gradually disappeared.
However, there are a few that have become more popular with users and that are potentially more suited to highervolume manufacturing, and, for clarity, these are briefly described below.

\subsection{Stereolithography}

The stereolithography (SL) process, predominantly of 3D Systems Inc. [21], is a process for fabricating a solid plastic part out of photosensitive liquid using a directed focused laser beam (usually a UV laser) to cure the liquid into a solid part. The part is built by the repeated scanning of successive layers, one on top of the other, that are derived from the native CAD file via the STL file format. The sliced layers are successively scanned until the part is complete. As the part is essentially built up from a liquid, there is a need for support structures to connect the part to the build platform and to support overhanging or island features that are produced during the build. There are a few other brands, mainly in Japan, that are based on very similar principles [22].

\subsection{Fused deposition modelling}

Fused deposition modelling (FDM) is a solid-based RP system in which a filament of wax or polymer is extruded onto the existing part surface from a work head to complete each new layer. The work head is controlled in the $X-Y$ plane for each layer and then moves up a distance equal to one layer in the $Z$ direction. The starting material is solid filament with a typical diameter of $1.25 \mathrm{~mm}$ fed from a spool into the work head which heats the material to $0.5^{\circ} \mathrm{C}$ above its melting point. The molten material is solidified and cold welded to the cooler part surface in $0.1 \mathrm{~s}$. The part is fabricated from the base up using a layer-by-layer approach. Materials that can be used by this process include investment casting wax and several polymers, such as ABS, polyamide, polyethylene and polypropylene; however, the ABS material is by far the most common.

\subsection{Selective laser sintering}

Selective laser sintering (SLS), or laser sintering (LS) as it is now increasingly being called, works in a similar way to stereolithography but uses a powder rather than a liquid photopolymer as its build medium. Developed at the University of Texas (Austin), it uses a moving laser beam to sinter heat-fusible powders in areas that correspond to sliced CAD data (via an STL file) one layer at a time to build the solid part. After completion of each layer, loose powders are spread across the surface using a roller. The powders are preheated to just below their melting point in order to facilitate bonding. Current materials being used in SLS include polyvinyl chloride, 
polycarbonate, polyester, polyurethane, ABS, nylon and investment casting wax. Also, ceramic and powder metals can be used. SLS has also been adopted to produce parts for downstream rapid tooling, namely tool inserts for injection moulding.

\subsection{Three-dimensional printing}

Three-dimensional printing (3DP) was developed at the Massachusetts Institute of Technology. This process uses an ink-jet printing head to eject a bonding material onto successive layers of powders. The powdered material could be any material, including plastics, ceramic, metal or cermets, among others.

\subsection{Jetting}

Jetting usually describes the use of ink-jet type processes to fabricate solid objects. Commercial systems exist that jet relatively low melting point wax-type materials to build up the three-dimensional objects. In recent years, there have been developments in jetting that include the deposition of photosensitive materials that are similar to stereolithography parts in appearance.

\section{DESIGN PROCESS}

The design process may simply be described as an imaginative integration of scientific related information, engineering technology and marketing for developing a profitable product. There is no single universally acclaimed sequence of steps that leads to a workable design. Different writers and designers have outlined the design process in as few as five steps or as many as 25. For example, Vidosic [23] describes it in eight steps, while Dieter [24] describes it in six steps which are as follows:

1. Need recognition. Prior to finding the solution to the problem, the designer must clearly understand and identify the needs of the user. This involves identification of customer's needs and their highlighting and analysis.

2. Problem definition. This requires the designer or others involved to develop a concise problem statement, identify requirements and limitations associated with the problem and obtain information.

3. Information gathering. This involves collecting information from sources such as handbooks, journals, standards, technical experts, the information superhighway and so on.

4. Conceptualization. Creativity is a critical ingredient in finding a solution to most engineering problems. Group brainstorming is one of the most popular ways to generate imaginative solutions.
5. Evaluation. This involves a thorough analysis of the design. It usually involves detailed calculation, often computer calculation, of the performance of the design by using an analytical model. Many cases involve extensive testing of an experimental model or a full-sized prototype.

6. Communication of design. This includes engineering drawings, information concerning quality assurance, bills of materials and instructions concerning operation and maintenance.

\section{PRODUCT DEVELOPMENT CYCLE}

With the advent of various design, manufacturing and engineering analysis packages, the evolution of new products has become more comprehensive and integrated to include process planning, manufacturing, distribution, field performance monitoring and even recycling. Figure 1 shows various steps and the data flow between them in a product development cycle [24].

This diagram clearly indicates the importance of manufacturing and assembly within product development. One important factor is the realization that over 70 per cent of the final product costs are determined at the design stage [25]. Also, the removal of the traditional 'over the wall' approach between design and manufacturing engineers and the emergence of concurrent or simultaneous engineering has resulted in attention being paid to every detail of manufacturing, assembly, serviceability and recycling at the design stage.

\section{DESIGN FOR $X$}

Concurrent engineering is an ideal environment for product development. Its objectives include improving quality, reducing costs, reducing cycle times, increasing flexibility and raising productivity and efficiency. The means of achieving these objectives are through cooperative teamwork between multiple disciplinary functions to consider all the interacting issues in marketing, design, production and retirement.

Design for $X$ (DFX) is the breeding ground and one of the most effective approaches to implementing concurrent engineering. DFX could take various forms, such as design for manufacturability, design for inspectability, design for the environment, design for serviceability, design for recyclability, design for reliability, etc. The phrase 'design for $X$ ' was first coined in the early 1990s [26, 27] and has been devised as an umbrella term, with DFX used as an umbrella acronym. Only one of these parameters, namely design for manufacturing (DFM), which later will be investigated with respect to RM, will be briefly discussed here. 


\subsection{Design for manufacturing}

Design for manufacturing (DFM) is a philosophy or mind-set in which manufacturing input is used at the earliest stages of design in order to design parts and products that can be produced more easily and more economically. Design for manufacturing is any aspect of the design process in which the issues involved in manufacturing the designed object are considered explicitly with a view to influencing the design. The results of implementing DFM have often been quite remarkable. For example, a production cost reduction of up to 50 per cent has been widely reported, and it has been implemented in a wide range of complex goods, including aircraft, cars and computers [28]. This has made DFM an imperative for many marketing/ assembly companies in the manufacturing industry.

Some basic design principles for efficient manufacturing are:

1. Develop a modular design. Design parts as a selfcontained component with standard interface to other components.

2. Use standard components.

3. Design parts to be multifunctional.

4. Design parts for multiuse (a mounting plate can be used to mount a variety of components).

5. Design for ease of manufacture and fabrication.

The first four rules are widely adopted (whenever possible) and common among various manufacturing processes. However, the last rule is more comprehensive and could differ according to the manufacturing processes adopted. These guidelines are well documented elsewhere [25, 29-31].

\subsubsection{DFM guidelines for injection moulding}

As the range of products being produced by RP and RM is quite comparable with that of the injection moulding of plastics, the rules associated with this process are discussed here. An introduction to injection moulding and the range of products produced by this process is given elsewhere $[\mathbf{3 2}, \mathbf{3 3}]$.

Only a few of the guidelines are given here:

1. Wall thickness consideration. Components with thin walls solidify faster than components with thicker walls, hence reducing warpage, twisting and, above all, production costs.

2. Uniform wall thickness. A non-uniform wall thickness will cause compression and expansion of molecules, resulting in compressive and tensile stresses. The stress in turn will result in cracks, crazing or fractures of moulded parts.

3. Avoiding sharp corners. These will produce tensile, compressive and shear stresses in moulded parts, resulting in stress concentration points which will lead to part failure.
4. Minimizing weld lines. When different flow fronts (resulting from obstruction within the mould or various gates) meet, weld or fusion lines are created. These are a source of weakness within the part and should be minimized during design.

5. Minimizing sink marks. These are formed when a thin section becomes solid sooner than a developed thicker section. Sink marks could be made less apparent by adequate consideration during design.

6. Draft angles. These are important for ease of removal of parts from moulds. The inclusion of draft angles at the design stage is very important, but often omitted.

7. Minimizing re-entrant features. An easy-tomanufacture part must be easily ejected from the die. Designing undercuts requires side cores. This in turn will require moving parts in the dies which adds to tooling costs considerably. Some parts containing features such as blind holes and gullies are simply impossible to manufacture without using very complex and expensive tooling arrangements.

8. Parting line. The direction of mould closure and parting line is also crucial in tooling and injected parts. Much consideration and deliberation are needed for their selection.

9. Ejection pin marks and gate marks. These could have an adverse aesthetic effect on the injection-moulded part. However, with adequate consideration their impact could be minimized.

\section{IMPACT OF RAPID MANUFACTURING}

\subsection{Rapid manufacturing and the product development cycle}

By considering the steps involved in Fig. 1, it is immediately obvious that RM could have a great impact on some of the steps indicated in this diagram.

\subsubsection{Generation of detailed drawings}

This stage of the product development cycle could be easily removed as the RM processes will utilize threedimensional CAD data directly to produce the parts without requirements for any drawings or dimensions. The removal of this step will require some cultural changes within the company as drawing-less manufacturing is something that is not common practice and will require some cultural change.

\subsubsection{Building prototypes}

Prototyping has traditionally been a well-established area within manufacturing companies employing highly skilled machinists and fine craftsmen. By the introduction of RP processes into some companies, different groups of highly trained and specialized personnel have 


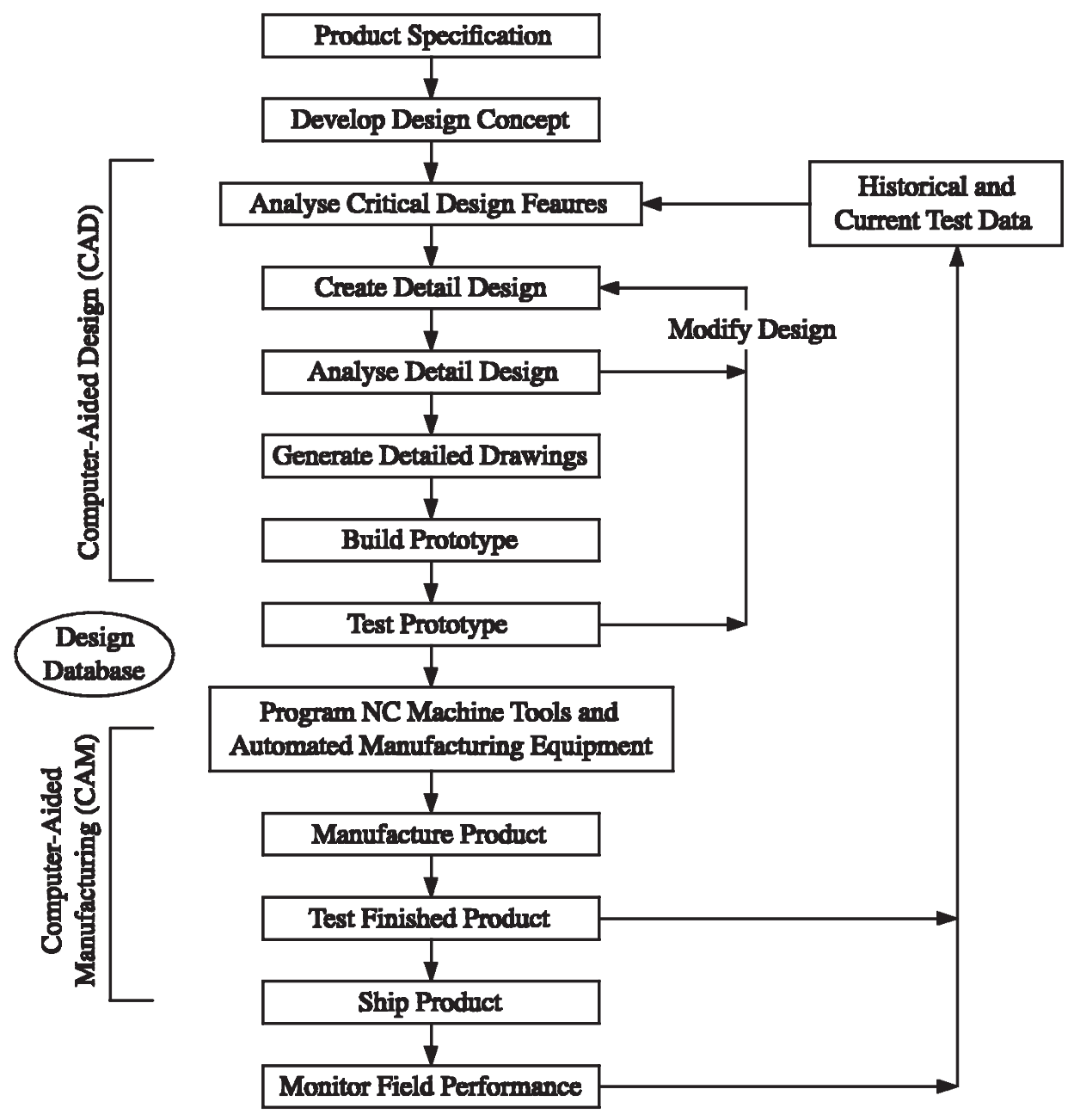

Fig. 1 Various steps in the product development cycle [23]

been involved in this aspect of the product development cycle.

Prototypes are traditionally expensive to produce owing to the lack of available tooling. Rapid prototyping has had a dramatic effect on the production of prototype components, but has been unable to make technical prototypes in the end-use material. These technical prototypes are therefore often produced by so-called 'soft' or 'rapid tooling' methods. However, as the processes and materials of RM improve, it will be possible to produce prototype parts on the same machines that will be used for the production of the final products, thus obviating the need for any prototype tooling. This implies that the skilled and specialized group of people currently employed in the production of technical prototypes may well need to be directed to other areas of product development.

\subsubsection{Numerical control programming and tooling design}

This is a time-consuming, labour-exhaustive and lengthy process within the product development chain, and RM will have an important impact on it. There will be no need to create and test numerical control (NC) or computer numerical control (CNC) programs, either for tool production [milling, drilling, electrical discharge machining (EDM), etc.] purposes or product manufacturing purposes. Selecting correct tools, designing and producing jigs and fixtures, monitoring tool life, etc., is also a time consuming task.

Also, initial capital investment needed for purchasing CNC machine tools and computer aided manufacturing (CAM) packages to develop $\mathrm{NC}$ programs will be avoided by the implementation of RM. Although currently the cost of investing in RM processes is high, with advances in the technologies and a larger market to sustain the production, the costs will decrease, and hence significant savings in machine investment will be achieved.

\subsection{Rapid manufacturing and design for $X$}

After a brief introduction to RM processes and highlighting of the importance of design for manufacturing, it seems appropriate to investigate the impact of RM 
on these aspects of the product development cycle. An attempt will be made to establish which of the already mentioned rules and guidelines will be removed or what new ones will be introduced by the implementation of the RM processes.

\subsubsection{Impact of RM on DFM guidelines for injection moulding}

As mentioned previously, in a manufacturing environment, RM processes will, in the first instance, be considered as an alternative to injection moulding. Rapid manufacturing, unlike injection moulding, is a tool-less process that does not involve any melting and subsequent solidification of materials within the confines of a tool. Therefore, problems of constant wall thickness (to aid the flow of material), avoidance of sharp corners and minimization of weld lines, sink marks, ejection pins, gate marks and draft angles will no longer need to be considered.

However, the significant impact of RM is on the guidelines associated with minimizing complex geometries and features such as undercuts, blind holes, screws, etc.
Incorporating such features in conventional injection moulding are not impossible but often require expensive tooling, extensive tool set-ups, testing runs, prototyping, etc. This inevitably leads to undesirable lead times and costs. Figure $2 \mathrm{a}$, shows a part containing a simple internal undercut being produced by a set of injection moulding tools containing a split core and forming pin. Also, Fig. 2b shows the formation of an external undercut with the help of a side core. It should be noted that creating simple parts by injection moulding, such as those shown in Fig. 2, requires tooling arrangements that are complex and expensive. Also, any simple modification in design requires a new set of tooling.

However, as RM is a tool-less process, the complexity of the part is not important, and any complex shapes or features produced by the CAD model can be directly translated into the final product. This is unheard of for any conventional manufacturing process.

In conventional manufacturing processes, such as injection moulding, the selection of the right location for the split line, in particular for asymmetrical and complex shaped components, is quite difficult and is

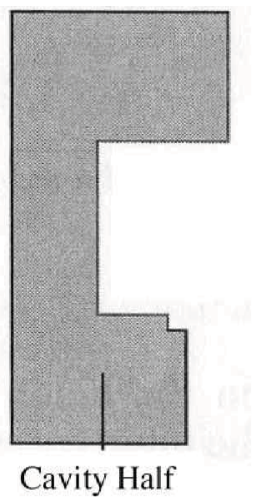

Cavity Half

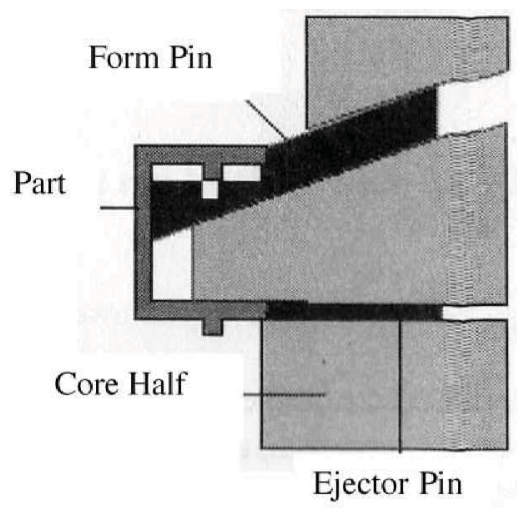

(a)

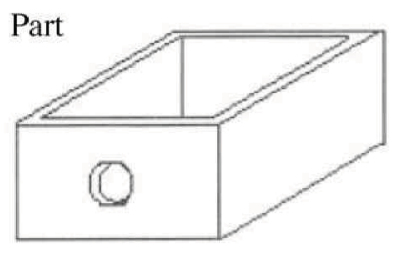

Cavity Half

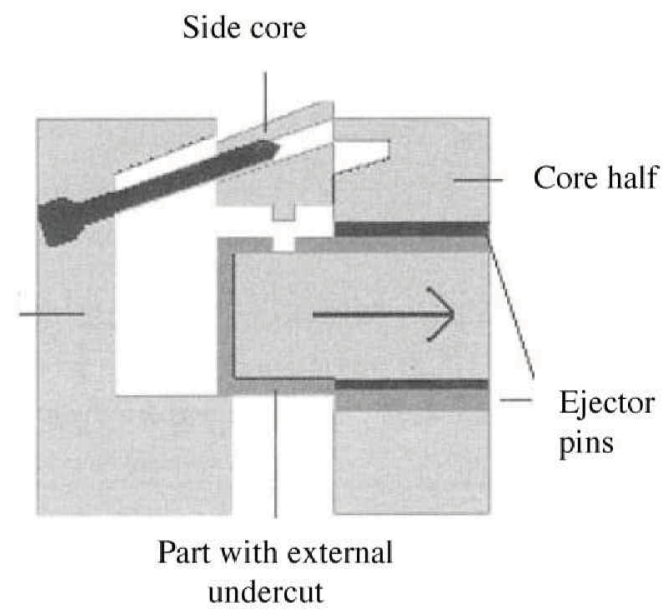

(b)

Fig. 2 Complex tooling for simple features [26]: (a) part with internal feature; (b) part with external feature 


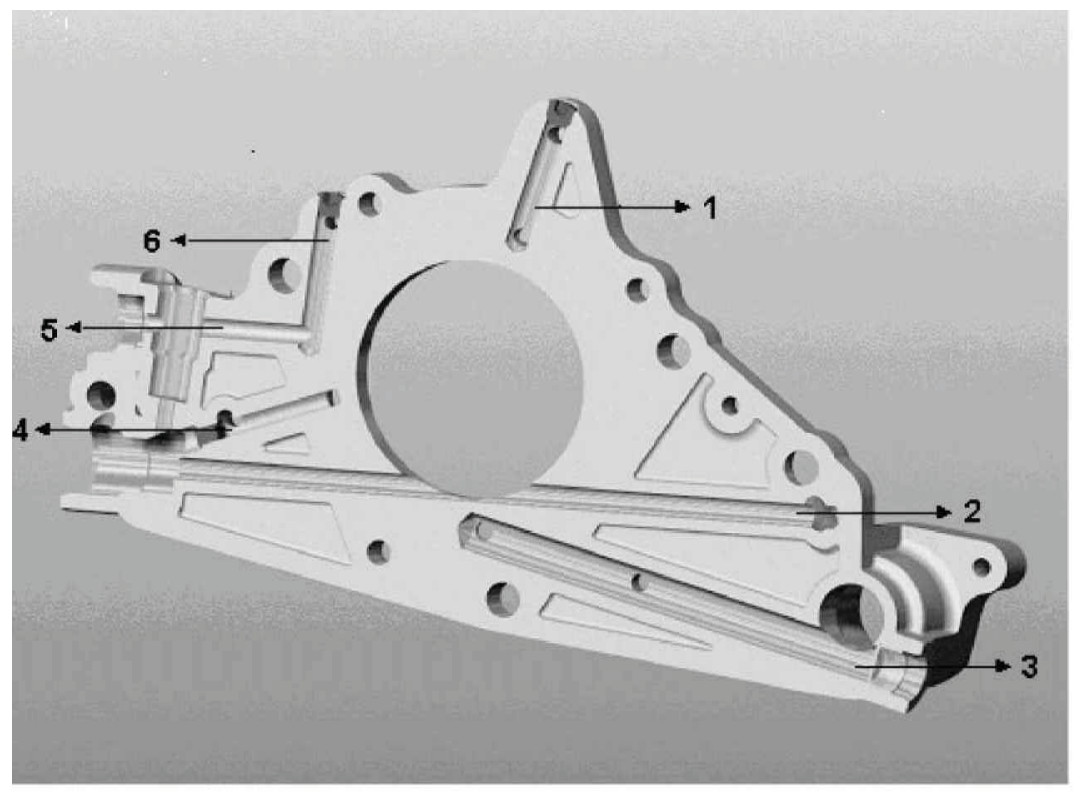

(a)

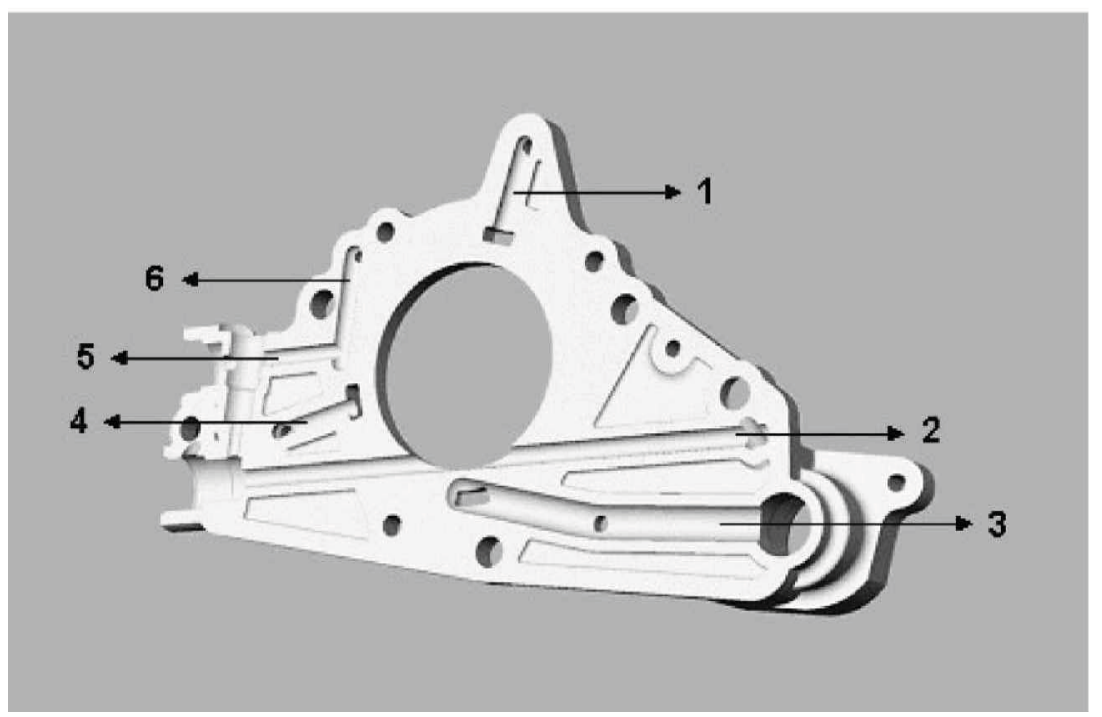

(b)

Fig. 3 Fuel injection system front plate [courtesy of Delphi Automotive (UK)]: (a) sectional view of CAD model for die-cast part; (b) sectional view of CAD model for SLA part

largely dependent on the experience of the tool designer. However, adopting RM processes and not using any tooling, designers will be entirely freed from this task.

Figure $3 \mathrm{a}$ shows a sectional view of a CAD model of the front plate of an injection fuel system that is currently being aluminium die cast, with internal channels 1 to 6 being subsequently machined and some being capped (1, 3, 4 and 6). The required machining and consequent capping result in increased production times and costs and also the possibility of fuel leakage during the service life of the part. This component has been re-evaluated for production by injection moulding and, concurrently, a feasibility study of its manufacture by a plastic RM technique has also been considered. Figure $3 \mathrm{~b}$ shows a cross-section through the redesigned part, representing the same part but after redesign and modelling for RM. It is clear that blind holes (1, 3, 4 and 6) have been incorporated in the part. This has been achieved during the production of the component by the RM process, and would be impossible by conventional manufacturing techniques without the need for subsequent machining and capping. In addition, the holes have been produced with a non-straight aspect which would not have been possible with conventional drilling.

Although this is a relatively simple example, it clearly demonstrates the ability of RM to produce complex parts with otherwise impossible-to-create internal geometries, and also demonstrates how subsequent machining and assembly issues can be removed. This would ultimately result in a reduced production time and cost 
and would greatly improve the operation of the component as there would be no risk of fuel leakage in these sealed cavities.

\section{CONCLUSIONS AND SUGGESTIONS FOR FURTHER WORK}

The aim of this paper has been to investigate the impact of recently developed RM techniques on the design process in general and the product development cycle in particular. To this end, an existing classical approach to the design process and its evolution into a product development chain have been introduced, and a number of steps involved in developing a product have been mentioned. The various aspects of design within a concurrent engineering environment have been explained. Design for manufacturing has been introduced, and a number of guidelines and rules that are applied at the design stage for the injection moulding process have been briefly explained.

Then, the impact of RM processes on various aspects of manufacturing, such as the generation of detailed drawings, building prototypes, NC programming and tooling design, have been investigated. Also, the impact of RM on guidelines for designing for injection moulding, for which RM is considered to be a suitable replacement, have been explored.

From these investigations, which are believed to be the first of their kind, it can be concluded that, theoretically, RM processes can easily accommodate all the established guidelines. However, the practicality of this is the subject of further field work. Hence, it is suggested that, in the next phase of the research, a number of newly designed parts or parts being redesigned for RM be manufactured and the above-mentioned effects be practically established.

\section{REFERENCES}

1 Hague, R., Campbell, I., Dickens, P. and Reeves, P. Integration of solid freeform fabrication in design. In Solid Freeform Fabrication Symposium, Austin, Texas, August 2001 (University of Texas).

2 Jacobs, P. F. From stereolithography to LENS: a brief history of laser fabrication. In International Conference on Metal Powder Deposition for Rapid Manufacturing, San Antonio, Texas, 8-10 April 2002.

3 Shishkovsky, I. Synthesis of functional gradient parts via RP methods. Rapid Prototyping J., 2001, 7(4), 207-211.

4 Morgan, R., Sutcliffe, C. J. and O'Neill, W. Experimental investigation of nanosecond pulsed Nd:YAG laser remelted pre-placed powder beds. Rapid Prototyping J., 2001, 7(3), 159-172.

5 Hague, R. J., Campbell, I., Dickens, P. and Reeves, P. Integration of solid freeform fabrication in design. Time Compression Technol., August 2002, 10(4), 48-53.
6 The solid future of rapid prototyping. Econ. Technol. Q., 24 March 2001, 47-49.

7 Ulrich, K. T. and Eppinger, S. T. Product Design and Development, 1995 (McGraw-Hill, New York).

8 Dickens, P. and Hague, R. EPSRC Grant Reference GR R13517/01. Design for rapid manufacture.

9 Shen, J., Steinberger, J., Gopfert, J., Gerner, J., Daiber, F., Manetsberger, S. and Ferstl, S. Inhomogeneous shrinkage of polymer materials in selective laser sintering. In Solid Freeform Fabrication Symposium, Austin, Texas, 7-9 August 2000.

10 Volpato, N., Childs, T. H. C. and De Pennington, A. Accuracy effects of shelling a part in the SLS process. In Solid Freeform Fabrication Symposium, Austin, Texas, 7-9 August 2000.

11 Suping, Y., Murkami, T. and Nakajami, N. Accuracy study on laminated object manufacturing. In Solid Freeform Fabrication Symposium, Austin, Texas, 7-9 August 2000.

12 Fadel, G. M. Accuracy issues in CAD to RP translators. Rapid Prototyping J., 1996, 2(2), 4-17.

13 Michaeli, W. M. L. Rapid tooling for injection mouldinghow close are injection moulded prototypes to series parts. In Proceedings of 8th European Conference on Rapid Prototyping and Manufacturing, Nottingham, 6-8 July 1999.

14 Reeves, P. Reducing the surface roughness deviation of stereolithography components. $\mathrm{PhD}$ thesis, University of Nottingham, October 1998.

15 Dickens, P. Advances in rapid manufacturing. SME technical paper PE01-176, 2001.

16 Hopkinson, N. Rapid manufacturing-using additive manufacturing processes for production. Time Compression Technol. Mag., August 2000, 8(4).

17 Wohlers, T. Wohlers report: rapid prototyping and tooling state of the industry. In Annual Worldwide Progress Report, 2001 (Wohlers Associates, USA).

18 Cooper, K. G. Rapid Prototyping Technology-Selection and Application, 2001 (Marcel Decker, New York).

19 Groover, M. P. Fundamentals of Modern Manufacturing Materials, Processes and Systems, 2nd edition, 2002, p. 772 (John Wiley, New York).

20 Castle Island web site $<$ http://home.att.net/ castleisland $/>$.

21 3D Systems Incorporated, Valencia, California, www. 3Dsystems.com.

22 Kai, C. C. and Fai, L. K. Rapid Prototyping Principles and Applications in Manufacturing, 1977 (Wiley (Asia), Singapore).

23 Vidosic, J. P. Elements of Design Engineering, 1969 (Ronal)

24 Dieter, G. E. Engineering Design, 1991 (McGraw-Hill).

25 Boothroyd, G., Dewhurst, P. and Winston, K. Product Design for Manufacture and Assembly, 1994, p. 2 (Marcel Dekker, New York).

26 Gatenby, D. A. and Foo, G. Design for $X$ (DFX): key to competitive, profitable products. AT\& $T$ Tech. J., MayJune 1990, 2-13.

27 Keys, K. System life cycle engineering and DF ' $\mathrm{X}$ '. IEEE Trans. Components, Hybrids and Mfg Technol., March 1990, 13(1), 83-93.

28 Fox, S., Marsh, L. and Cockerham, G. Design for manufacture: a strategy for successful application to building. Construction Managmt and Econ., 2001, 19, 493-502. 
29 Poli, C. Design for Manufacturing, A Structured Approach, 2001 (Butterworth-Heinemann, Boston, Massachusetts).

30 Bryce, D. M. Plastic Injection Molding, 1997 (Society of Manufacturing Engineers).

31 Bralla, J. G. Design for Manufacturing Handbook, 1998 (McGraw-Hill, New York).
32 Degarmo, E. P., Black, J. T. and Kosher, R. A. Materials and Processes in Manufacturing, 1997 (Prentice-Hall, New York).

33 Kalpakjian, S. and Schmid, S. R. Manufacturing Engineering and Technology, 2001 (Prentice-Hall, New York). 